\title{
TRENDS AND BENEFITS OF E-CUSTOMER RELATIONSHIP MANAGEMENT
}

\section{BIBHUTI B PRADHAN \& JYOTI R DAS}

Department of Management, Siksha 'O' Anusandhan (Deemed to be University), Bhubaneswar, Odisha, India

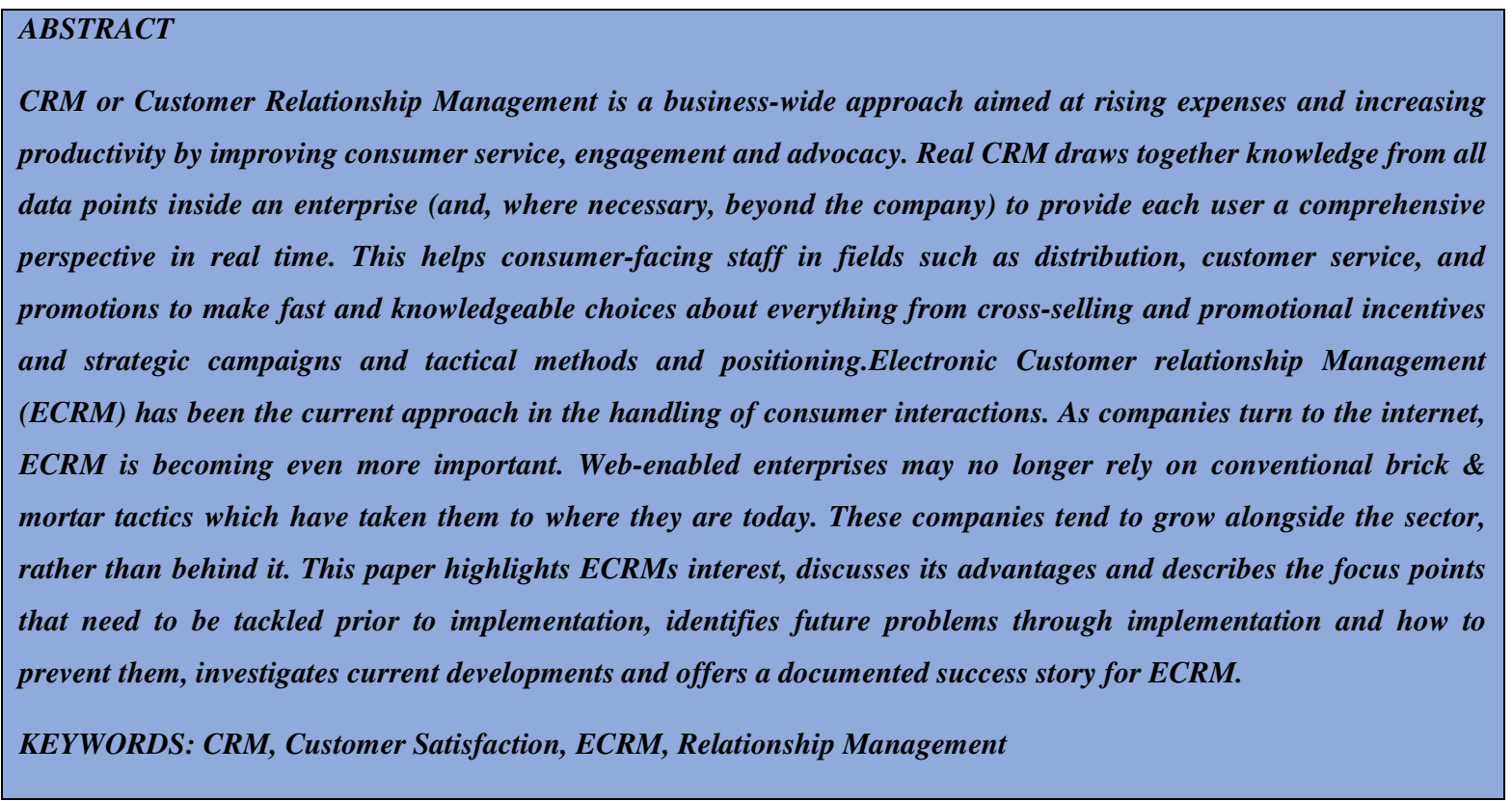

Received: Jun 08, 2020; Accepted: Jun 28, 2020; Published: Aug 26, 2020; Paper Id.: IJMPERDJUN2020899

\section{INTRODUCTION}

The modern concept of online customer relationship management[1] (ECRM) requires to be trained by all companies engaged with on-line company to company and/or business to market sales. According to Romano, ECRM seeks to draw and retain commercially beneficial consumers and remove the least productive ones. Romano and Fjermestad are confident that ECRM should continue to grow as a significant field of research within MIS and associated theoretical disciplines such as computer science, marketing and psychology. This, instead, is the partnership between consumer preferences and organizational delivery incentives.Company and customer sales over the Web are growing every day[2].

There are a variety of common explanations that consumers shop products. A survey of 69 retailers by Forrester Research showed that comfort was the number one factor listed (83 percent) for online vs. off-line sales. The fact that customer care ranks near to the edge of the online shopping list indicates that consumers are able to exchange decent off-line support rates for the ease of online purchasing. Looked at another way, internet users will not come to the websites of businesses with extremely strong hopes for the quality of service.Online retailers need to realize, though, that first-time shoppers at their pages are not automatically, or even probable, to become regular customers. A research undertaken by the Boston Consulting Group showed that 66 per cent of online consumers who shop on a specific platform would never purchase a second. Such findings will be a wake-up call to webenabled businesses that there is a clear market gap to tackle and that increased revenues await certain businesses 
who are fast to find a way to fill this void. ECRM will help companies[3] face the obstacle.

The ease of shopping online will get shoppers through the virtual door, but the overall consistency of the consumer service is what keeps them going back through the same door.

Web-enabled companies ought to realize that, as the selling expense of a current user is $\$ 7.0$ over the internet vs $\$ 35.00$ in order to attract a potential site consumer. However, Keen estimates that the share of enterprise-to-business marketplaces utilizing ECRM systems would expand from 4 percent in 2000 to over 49 percent in 2005. Investing in ECRM systems would provide businesses with the resources they need to develop, sustain and expand their competitive edge in their market spaces.In the end, it's about business sustainability. When the ECRM requirement has been identified, this paper would explain the benefits of ECRM solutions, address the key focal points to remember when introducing an ECRM approach, define possible drawbacks through implementation, look at current ECRM developments and present a validated ECRM success story[4].

\section{BENEFITS}

A new analysis by McKinsey \& Co. showed that a 9 per cent rise in returning customers would contribute around 9 per cent to the earnings of the business. In the other side, a 9 percent reduction in overall advertisement spending expected to draw potential tourists contributes to the bottom line just 0.6 per cent. In fact, holding current clients satisfied is more lucrative than chasing a bigger amount of prospective buyers, particularly though the risk of gaining such additional future consumers is minimized by a business[5]. The only approach to hold these current consumers satisfied is to provide them with service at their own terms.In a new report, Anderson Consulting showed that by strengthening the capacity to handle client interactions, a small $\$ 0.99$ billion high-tech business would earn as much as $\$ 129$ million in revenues. Anderson Consulting has reported that ECRM success is due to as many as 65 per cent of the gap in revenue gains between mediocre and high-performing businesses. This data shows that the well-planned introduction of an ECRM program is creating a positive scenario for both consumers and enterprises. Improvements in the overall consumer experience result in improved customer loyalty and in turn has a beneficial impact on the productivity of the business.A successful implementation of the ECRM will accomplish the following objectives:

\section{Gaining Customer Satisfaction}

The successful ECRM program enables an organization to communicate with its customers using a clear, coherent speech, irrespective of the medium of contact. That is because everybody in an organization, through ECRM applications, has links to the same account background and client records. Captured details from an ECRM program allows an organization to recognize the real expense of attracting and maintaining specific clients. Using such details helps the organization to spend its energy and money on its most productive customers.Classifying one's "best" customers in this manner helps a company to handle them more efficiently as a luxury category, with the assumption that treating any consumer precisely the same way is neither appropriate nor advisable.

Personalization[6] is one method that a business should introduce in search of consumer satisfaction. Using data from multiple sources including consumer accounts, clickstream data and transaction processes, personalization software tools create real-time identities for and user.Any time a single user shops the company's web site, the machine chooses the best bid based on what it "knows" about that person. When a person takes or refuses a bid, the design engine incorporates the client information into his / her profile and makes it accessible for more educated potential deals. In business-to- 
business pages, personalization is similarly successful. Many find its main importance to be a navigational aid in places providing a broad variety of goods, resources and information. The principle of automation is a time-saving process that drives the ads and content shown on a consumer value focused website.

A recent advancement in personalization software is the scenario server from ATG[7] which monitors the behavior of a customer over an extended period of time. This will assist in scheduling strategic marketing strategies, such as creating new deals on the website or launching a new program for email advertising. Additionally, there is a movement towards the integration of collective filtering and decision-making centered on guidelines within the same software package. For ex. Waltner suggests that a merchant might write a rule for this new variety of personalization software which restricts the types of products offered by collaborative filtering to the two most lucrative ones.

\section{Better Marketing Performance}

With accurate consumer details[8] from an ECRM program, a corporation may forecast the sort of goods a client is willing to buy as well as the pace of sales. This insight allows a company to develop more efficient and oriented marketing / sales strategies in the short to medium term, intended to target the targeted customer group. ECRM facilitates more tailored initiatives and camp efficacy reporting.From different angles, consumer results may be evaluated to figure out the aspects of a marketing strategy have the biggest effect on revenue and productivity. Additionally, segmentation of customers can boost marketing efforts. Grouping consumers with associations due to their preferences helps an organization to better sell different goods to representatives of the focus groups.

\section{Better Customer Care and Delivery}

An ECRM program offers a centralized Consumer[9] Data Repository. This helps an organization to meet consumer demands at all possible touch points easily and effectively, avoiding the stressful and time-consuming "search" for assistance from the client. ECRM enabling tools provide search engines, live assistance, e-mail processing, news feeds / content management and multi-lingual help.Two main forms of enhancing customer satisfaction and assistance are by email promotions and direct mail. A comprehensive contact marketing platform can help bring sales to a wide variety of prospective clients and can tailor the delivery of the deal. Extremely tailored solutions to e-mail and direct mail, though, provide seen stronger outcomes. The best methods promote the delivery at the right moment of the right deals to the right clients.An alternative approach to support clients is by better contact with the call center. User deserve quality support and prompt outcomes as consumer's phone into a contact center. The ECRM call center system helps monitor and control call routing. Unit managers get the details they need to fix challenges and troubleshoot them easily. Furthermore, members of call centers produce orders that are sent to delivery directly, thereby delivering an optimized consumer interface.

\section{Greater Productivity and Reducing Prices}

Information mining, which information is processing to discover potential linkages between data sets, will save precious human capital. Use the same basic facts, combining consumer details into a centralized account enables management managers, selling staff and other divisions inside an organization to exchange knowledge and collaborate against similar business goals. Examples of these involve detecting unproductive / underused services, tighter expense monitoring, improved pipeline planning and establishing practical project indicators and benchmarks to calculate investment returns[10]. 


\section{Developing Market Plans that Attract Consumers}

The purpose of this move is not to attempt to shape the consumer to the interests of the business but to respond to the consumer and seek to build solutions that can help both. It is necessary to deliver what consumers are now seeking and forecast what they are going to want in the future. Which can be accomplished by supplying consumers with a range of current access networks, such as e-mail, telephone and fax, and by planning for potential access platforms, such as wireless communications.It is easy to deliver opportunities rather than challenges if an organization empowers its customer support representatives to do so right away, and if consumers have exposure to the new deals and discounts from their own medium of convenience.

\section{To Restructure Market Operations}

Beginning with company through ECRM may entail radical operational reform to decide which departments / functions actually represent the consumer and which ones just contribute to the overhead. Administrative time and expense will collapse after the detection and trimming of obsolete headcount. A big consideration here is that the improvements needed during an execution of the ECRM can only be feasible with buy-in from top management levels and other stakeholder's corporate responsibility.Successful systemic progress is not only going to materialize on its own. Senior management is responsible for ensuring that all workers recognize the importance of the reforms, how they can profit from the current system, and how it can improve their capacity to support their clients.

\section{Reconfiguration Work Operation}

Changes in departmental positions and duties with the retooling of corporate operations would allow different job procedures to be implemented. Here the options are to take the conventional step-wise method or an adaptive one to increase productivity in the job. Departments are viewed as independent management units according to the step-wise methodology. This never produces successful outcomes because growing department's priorities may become too parochial, and divisions continue to fight internally for their own benefit at the cost of what's better for the business.This helps to deliver better outcomes as it understands the interdependencies between the different functions / departments of the enterprise and how they build the wider view of the entity as a whole. Secret complexity can be exposed in an interconnected structure as well as incentives for improved productivity.

\section{Learning and Development}

This focus point of applying ECRM is probably the most significant one. Based on the number of participants, training periods can differ from business to organization. Training with staff will take place until the current ECRM program is introduced to guarantee a seamless transfer for customers. Examples with training involve taking participants to training centers at substantial expense or getting in an on-site trainer. Both preparation and the resources used by existing, new and prospective workers will be properly recorded.The importance of ECRM program would decay rapidly without a documentation management scheme. An organization can expect to invest between $6 \%-8 \%$ of the overall adoption of the ECRM on training. 


\section{TRENDS}

Recent advances in the ECRM area include a CRM product evaluation / procurement program, hosting of CRM system software and utilizing Online Analytical Processing (OLAP) resources to build Consumer Awareness to improve ECRM's effectiveness.

\section{Selection Process for CRM Products}

IT enol is a start-up firm in California that delivers a software named CRM Software Selection Manager to simplify the steps involved in selecting and integrating a CRM kit. This article span both stages, from identifying the specifications of a client and reviewing suppliers to securing contracts and creating buying orders. After setting up of the program, customers cooperate to determine market priorities and create a suggestion request (RFP). When an RFP is available, IT enol contacts vendors, and vendor reps may collaborate in response online. The software is open to CRM providers at no fee.ITenol offers web-accessible project management services after a client has bought a CRM kit, to support the organization configure the program.

\section{Hosted Apps for CRM Components}

The market for hosting full-fledged ECRM systems is shrinking, partly due to the current economic environment and partly because configuration rates requested by client organizations to satisfy their unique demands are too difficult to deliver in a bundled solution. Nevertheless, the demand for hosting CRM product apps, such as a Satmetrix host kit to gage consumer service, is even greater. The amount of expenditure needed is much smaller, but the host apps have additional value for consumer businesses.

\section{Client Awareness}

As discussed earlier, incorporation of the legacy systems of an organization, especially its ERP system, with ECRM technology is crucial to the effectiveness of every ECRM implementation. Customer Intelligence is based on adapting the knowledge gained from market experience to ECRM approaches and then relying on those techniques to create interest in consumer relationships. To have near-real-time exposure and review of results, the CI enabling technologies need to be strongly coupled with the ERP and ECRM solutions.OLAP resources, accessible from organizations like Cognos, are the central supporting technology that allow Customer Intelligence to conduct the sophisticated analytics needed. OLAP software allows predictive analytics, data mining, and data analysis required to discover secret associations in consumer data that contain the keys to consumer behavior awareness and customer interest determination.

\section{CONCLUSIONS}

ECRM has evolved and the idea is here to remain, whether the label sticks or not. This paper has looked at ECRM's latest performance at Hewlett-Packard. Recent developments in the area have been discussed, most prominently combining CI with ECRM approaches to achieve a better understanding of the dynamics of consumer behavior and valuation. It has discussed the kinds of problems that can surround an introduction of the ECRM and how to prevent them. Furthermore, it defined the key problems that organizations ought to address at the ECRM deployment threshold.

Finally, it looked at the customer-centered and organizational benefits of adopting an ECRM approach, recognizing that ECRM strategies would only work when companies win over their clients. ECRM became the new brand slogan and was readily adopted by internet-savvy consumers. This article addressed what ECRM is. Has discussed the 
advantages and what the new developments are. Companies have learned they ought to let their customers compete first in order to survive. This can be done by delivering the best commodity at the right price and on schedule. Businesses ought to incorporate an efficient ECRM program to do this. Organizations very existence relies on how effectively they adopt ECRM.

\section{REFERENCES}

1. C. R. Management, "From social media to Social CRM," Business, 2011.

2. I. G. Cristea and D. Mocuta, "Customer relationship management," in Proceedings of the 31st International Business Information Management Association Conference, IBIMA 2018: Innovation Management and Education Excellence through Vision 2020, 2018, doi: 10.33619/2414-2948/51/21.

3. R. M. Mohammad, F. Thabtah, and L. Mccluskey, "Phishing Websites Features," Ieee. pp. 1-7, 2013, doi: 10.1016/j.bios.2004.09.003.

4. F. B. and S. Maklan, Customer Relationship Management Concepts and Technologies. 2013.

5. M. Ehsani, B. Izadi, Y. J. Yoon, K. M. Cho, H. Koozechian, and F. Tojari, "An investigation of the effect of fan relationship management factors on fan lifetime value,” Asian Soc. Sci., 2013, doi: 10.5539/ass.v9n4p248.

6. E. Toch, Y. Wang, and L. F. Cranor, "Personalization and privacy: A survey of privacy risks and remedies in personalizationbased systems," User Model. User-adapt. Interact., 2012, doi: 10.1007/s11257-011-9110-z.

7. P. Oberoi, C. Patel, and C. Haon, "Technology sourcing for website personalization and social media marketing: A study of e-retailing industry,”J. Bus. Res., 2017, doi: 10.1016/j.jbusres.2017.06.005.

8. S. Alavi, V. Ahuja, and Y. Medury, "An empirical approach to ECRM-increasing consumer trustworthiness using online product communities,” J. Database Mark. Cust. Strateg. Manag., 2011, doi: 10.1057/dbm.2011.12.

9. P. Ajitha, R. M. Gomathi, and A. Sivasangari, "Design of online shopping cart using prestashop e-commerce," Int. J. Adv. Res. Eng. Technol., 2019, doi: 10.34218/IJARET.10.5.2019.014.

10. A. Miremadi and A. Abdolhosseini Khaligh, "Abstract - Main.pdf," in The Impact of eCRM on Loyalty and Retention of Customers in Telecommunication Sector, 2011. 